Journal of Social Sciences 5(3): 177-182, 2009

ISSN 1549-3652

(C) 2009 Science Publications

\title{
Assessment of Marketing Orientation Concept in Jordanian Service Industry
}

\author{
${ }^{1}$ Shaker Ismail, ${ }^{1}$ Mustafa Al Shaiekh and ${ }^{2}$ Mamdouh Al Ziadat \\ ${ }^{1}$ Department of Marketing, Philadelphia University, Amman, Jordan \\ ${ }^{2}$ Department of Marketing, Applied Science University, Amman, Jordan
}

\begin{abstract}
Problem statement: The objective of this study was to explore the extent to which the concept of marketing orientation was clear and adopted by Jordanian service firms, focusing on the financial sector. Approach: Based on an empirical fieldwork. Results: The study concluded that the majority of Jordanian financial service firms had a misconception of marketing orientation concept. They believed that they exercise marketing orientation concept, while their actual practice of selling orientation. Conclusions: The study also concluded that the majority of these firms kept strategic planning at the top management level. Statistical testing showed that the length of experience in business was an important factor in the firm's clarity of the concept of marketing orientation. Several implications of the findings and recommendations were finally presented.
\end{abstract}

Key words: Marketing orientation, one-way ANOVA testing, strategic planning, marketing practices

\section{INTRODUCTION}

Marketing activities do not take place in a vacuum. The marketing environment which includes competitive, economic, political, legal and regulatory, technological and social cultural forces surrounds the customer and affects the marketing mix. The effects of these forces on buyers and sellers can be dramatic and difficult to predict. They can create threats to marketers, but they can also generate opportunities for new product and new methods of reaching customers ${ }^{[1]}$.

Marketing concept: A philosophy that an organization should try to provide products that satisfy customers' needs through a coordinated set of activities that also allows the organization to achieve its goals.

Marketing as a distinct discipline was borne out of economics around the beginning of this century. As the discipline gained momentum and developed through the first three quarters of the twentieth century, the primary focus was on transactions and exchanges. However, the development of marketing as a field of study and practice is undergoing re-conceptualization in its orientation from transactions to modern concept, marketing orientation ${ }^{[2]}$. The concept is often referred to as: "Marketing Orientation" (MKO) concept.

Related work: Mark cross and others ${ }^{[3]}$, made a survey of 283 salespeople provides the database that was analyzed using structural equation modeling. Prior studies suggest that both company and salesperson customer orientation has a positive effect on performance. The findings of this study suggest that a salesperson's customer orientation completely mediates the relationship between company customer orientation and salesperson performance. Thus, the influence of a company's customer orientation on salesperson performance acts through the customer orientation of the salespeople. The study reinforces the importance of customer orientation and the role of salespeople in putting customer orientation into practice.

$\mathrm{O}^{\prime}$ cass and Liem Viet ${ }^{[4]}$. Founds that organizations with a strong innovative culture appear to recognize that building a successful brand; depends not always on the interpretation of feedback received from current customers and competitors, but instead on organizations' ability to innovatively develop unique ways of delivering superior value to customers. The findings were consistent with this advice to both market orientation and innovative culture. The findings indicate that market orientation is a response partially derived from the organization's innovative culture; it was also found that organizational culture was relatively more important than market orientation in affecting organizational performance.

A study of Alan and others ${ }^{[5]}$, was conducted to determine the relationship between a firm's role in the competitive environment and the appropriate strategies to use. Using firms sampled from China, it was found that market-oriented and relationship marketing-

Corresponding Author: Shaker Ismail, Department of Marketing, Philadelphia University, Amman, Jordan 
oriented strategies are both important for market leaders and market-oriented strategies are the best for market challengers, while relationship marketing-oriented strategies serve market followers and market nichers best.

The study of Farrelly and Quester ${ }^{[6]}$. Found that the effects of marketing orientation on the two most important relationship marketing concepts, namely trust and commitment. The sponsorship relationship is the focus of an empirical investigation aimed at uncovering the potential effect of market orientation, exhibited by both parties of the sponsorship dyad, upon trust and commitment. By selecting the leading sponsorship property in Australia, the Australian football league, the majority of key Australian sponsors were included in this study, allowing the authors to draw managerial implications of direct relevance to other sponsors and properties aiming to secure long lasting sponsorship relationships.

Problem of statement: In Jordan as in several other developing countries, it is generally believed that some business managers have misconceptions about marketing orientation concept and that they confuse it with sales and product orientation. Very often this lack of clear understanding of marketing orientation concept represents a very narrow vision of doing business today.

Despite its importance the concept of marketing orientation has not, generally, received sufficient attention in the literature, particularly in developed countries. In Jordan, as hinted above, it was generally indicated that this concept is somehow vague. In highly competitive markets, with rapidly changing environment, this can be more dangerous. Managers, with an unclear vision of marketing orientation, may run the risk of overlooking strategic opportunities and exposing their organizations to a variety of environmental threats. This study examines this issue in the Jordanian service firms with a particular reference to the financial sector.

Research objectives: This study attempts to explore the extent to which the concept of marketing orientation clearly understood and adopted by Jordanian service firms with a particular reference to the financial sector. This study is cause effects in nature and seeks to answer the following research questions:

- To what extent is the concept of marketing orientation understood by business managers in service firms
- Who are the major participants in the process of marketing orientation

- How do business managers perceive the importance of marketing orientation concept

- Are there statistical differences in the firm's clarity of the concept of marketing orientation due to organizational demographics (experience, number of employees and capital)

Significances of the Study: This study is expected to contribute significantly to a better understanding of how Jordanian business managers in the financial sector perceive the (MKO) concept and how they can use of it in their organizations. The study is also expected to make recommendations to business managers on the critical role of marketing orientation in doing business, in competitive markets.

Orientation of marketing practices: Pre-industrial society was largely based on agricultural economy and the trade of art and artifacts. During the agricultural days, most farmers sold their produce directly in the bazaars. Similarly, artisans sold their arts and artifacts at these markets. Consumers and producers gathered together face-to-face for trading products. The role of the producer was not separated from that of the trader and the producer functioned as both 'manufacturer' and 'retailer' of its own products. Also, producers and consumers developed strong relationships that led to the production of customized products made by the artisans for each customer. Similarly, relational bonding between traders was also quite prevalent, partly because of the need to do business with others you could trust. Thus, ongoing trade relationships were a critical element of business practices in the pre-industrial era where ownership was linked with the management of business. As a consequence, consumers and producers had direct relationship with each other ${ }^{[7]}$.

We can see that relationship orientation in marketing was evident during the preindustrial era. Direct interaction between the producers and consumers necessitated cooperation, reliance and trust among marketing actors. Evidence suggests that these relationships sometimes continued for generations as producers and consumers trusted each other's family and clans, the relationship orientation in marketing and trade continued into the early years of the Industrial Revolution and the emergence of capitalism, some of the efforts adopted by marketers during this period to build and maintain relationships with buyers ${ }^{[8]}$. 
Marketing practices during early industrialization were also highly individualized, relationship oriented and customized. Many products were manufactured on a custom basis for rich individuals or industrial customers. The design and tailoring of clothes, the creation of jewelry, watches, home furnishings and other consumer products were customized. Marketers rarely had to consider inventories of finished products and publishers sold textbooks for which a demand already existed ${ }^{[9]}$.

Practice in the Industrial Era was with the advent of mass production and mass consumption that marketers began to adopt a more transactional approach. Emergence of mass production and mass consumption resulted in key consequences. First, people moved away from small subsistence farms to jobs in industrial towns and needed retailers to supply assortment of basic conveniences of food, shelter and clothing ${ }^{[10]}$. Secondly, manufacturers were motivated to produce in mass quantities given the associated economies of scale. On the one hand, economies of scale helped these manufacturers to lower the cost of goods and hence prices of the products they sold and on the other hand, it increased the need to find markets for their products. Unable to sell the entire stock of produced goods, producers were confronted with an increased inventory of finished products. These market conditions gave rise to aggressive selling and the development of marketing institutions that were willing to bear the risks and costs of inventory ownership and storage. Wholesalers, distributors and other marketing intermediaries assumed the role of middlemen who, on the one hand, stored the excess production of manufacturers and, on the other hand, helped in locating and persuading more buyers to purchase goods and services ${ }^{[11]}$.

Thus emerged the transactions orientation of marketing whereby marketers became more concerned with sales and promotion of goods and less with building ongoing relationships. This shift was further accentuated during the Great Depression of 1929, when the oversupply of goods in the system heightened the pressure on marketers to find and persuade customers to buy their products. As competition intensified with excess capacity, sales transactions further increased. Many engaged in aggressive selling and competitive warfare $^{[12]}$.

The first development was the marketer's realization that repeats purchase by customers was critical, making it necessary to foster brand loyalty. Several marketing scholars also became interested in repeat purchase and brand loyalty behavior as early as World War II.

\section{MATERIALS AND METHODS}

Methodology: This study is exploratory in nature and relies on a field survey to collect the required data. All commercial banks in Jordan are included in the survey.

The unit of analysis is the service organizations. The survey was directed to the top management in each organization. Data collected from top managers, whose opinions reflected management practices in their organizations. A self-administered questionnaire was used to collect the required data.

A total of 39 commercial banks and financial institution were included in the survey. Using the drop and collect method, the researchers gave one questionnaire to the top manager in each firm and then collected it within 30 days. The highly controlled data collection procedures ensured $100 \%$ response rate.

The research tool: The require data was collected by means of a self-administered questionnaire, which was developed for this purpose. The questionnaire consists of ten questions. Question 1-7 examine the current practice and perception of marketing orientation concept and questions 8-10 are related to organizational demographics (years of experience, number of employees and capital).

The questionnaire was validated through a mini survey of academics and experts. Their opinions and comments were considered in the final version of the questionnaire. The reliability correlation was examined by Cronbach alpha and found $86 \%$, which is considered acceptable for this research.

The statistical package SPSS was used to analyzed data. Frequency analysis, descriptive analysis and oneway ANOVA were used. Table 1 describes demographics of the firm considered in the survey.

Table 1: Demographics characteristics of the firms considered in the survey

\begin{tabular}{lrr}
\hline Demographics characteristics & Number & Freq. (\%) \\
\hline Years of experience: & 5 & \\
Less than 10 & 16 & 12.9 \\
$10-15$ & 10 & 41.0 \\
$16-20$ & 8 & 25.6 \\
21 and above & 39 & 20.5 \\
& & 100.0 \\
No. of employees: & 5 & \\
Les than 50 & 8 & 12.9 \\
50-100 & 7 & 20.5 \\
101-150 & 9 & 18.0 \\
151-200 & 10 & 23.0 \\
201 and above & 39 & 25.6 \\
& & 100.0 \\
Capital (JD): & 10 & \\
Below 1000,000 & 6 & 25.6 \\
1001000-2 million & 23 & 15.4 \\
Greater than 2001000 & 39 & 100.0 \\
& & \\
\hline
\end{tabular}




\section{RESULTS}

Clarity of the (MKO) concept: Top managers in respondent firms were asked to choose, from a list of five alternatives, the nearest concept of marketing orientation practiced by their firms. The list included five philosophies that marketing management wants to design strategies that will build profitable relationship with the target consumers. Out of which one was considered to represent the correct concept as shown in Table 2. Figures in the table indicate that only $33 \%$ of firms checked the correct (MKO) concept. Table 2 shows that the most frequent response (33\%) was related to the concept of marketing orientation.

The first reading of the above results suggest that top business managers in Jordanian service firm were not likely to distinguish between (MKO) concept and others orientations. The majority did not seem to know what marketing orientation is $67 \%$. Thus, the concept of (MKO) was not likely to be properly understood and clear to them.

It may be useful at this stage to focus attention on the firms, which work according a specific marketing strategy philosophy; (85\% of the respondent firms revealed that they worked according to marketing strategy philosophy) for this group, further analysis revealed that only $33 \%$ of them were clear about (MKO) concept ( they checked the correct response). That is the majority of this group (67\%) did not seem to understand the (MKO) concept yet indicate that they used the misconception. Clearly they believed that they practiced marketing orientation philosophy in conducting their business. While in fact; it appears that they must have been doing some thing else.

Table 2: Alternative responses to the (MKO) concept

\begin{tabular}{lc}
\hline Alternatives of MKG orientation & Freq. (\%) \\
\hline $\begin{array}{l}\text { Management should focus on improving production } \\
\text { and distribution efficiency }\end{array}$ & 28 \\
$\begin{array}{l}\text { Achieving organizational goals depends on knowing } \\
\text { the needs and wants of target markets and delivering } \\
\text { the desired satisfactions better than competitors do }\end{array}$ & 33 \\
$\begin{array}{l}\text { Consumer will not buy enough of the firm's products } \\
\text { unless it undertakes a large-scale selling and promotion } \\
\text { effort }\end{array}$ & 8 \\
$\begin{array}{l}\text { Consumer will favor products that offer the most in } \\
\text { quality, performance and innovative features. This } \\
\text { strategy focus on making continuous product }\end{array}$ & 21 \\
improvements \\
$\begin{array}{l}\text { Marketing strategy should deliver value to customers } \\
\text { in a way that maintain or improve both the consumer's } \\
\text { and the society's well-being }\end{array}$ \\
\begin{tabular}{l} 
Total \\
\hline
\end{tabular}
\end{tabular}

\section{DISCUSSION}

Firms ideology in (MKO) concept: Table 3 demonstrate that the most frequent ideology followed buy the top management, it was (30\%) of the respondent firms revealed that they worked according to the strategy that attain economies of scale by producing a limited range of products, to minimize the production cost. And (25\%) of the respondent firms revealed that they worked according to the strategy that adopts a proactive search for market opportunities; use market information to increase its profit. Further analysis revealed that only (20\%) of them were clear about the (MKO) concept, (they checked the correct response). achieving organizational goals depends on knowing the needs and wants of target markets and delivering the desired satisfactions better than competitors do.

It may be useful at this stage to focus attention on the firm's strategy which follows to accomplish its goals. To ensure through understanding and accurate implementation of (MKO) concept; the research finding of the current study revealed that Jordanian services firms, the ratio goes up to $20 \%$, resulting from misconception of (MKO) concept relying on proactive manners for serving customers.

Perception of the importance of (MKO) concept: The analysis reveals that the overwhelming majority of the firms believed that MKG orientation concept was necessary for them $(96 \%)$. This reflect a strong faith in the benefits of (MKO) concept, further analysis in Table 4 measures attitudes of top business managers, in the respondent firms, towards the importance of (MKO) concept. Very clearly, the figures in the table reveal an overwhelming support for the role of (MKO) concept in guiding managers to achieve their objectives (100\%),

Table 3: Marketing ideology used

\begin{tabular}{lc}
\hline Marketing ideology used by marketing managers & Freq. (\%) \\
\hline $\begin{array}{l}\text { The idea that consumer will favor products that offer } \\
\text { the most quality, performance and features, }\end{array}$ & 10 \\
$\begin{array}{l}\text { and making continuous products improvements } \\
\text { Is to attain economies of scale by producing } \\
\text { a limited range of products, to minimize the } \\
\text { production cost }\end{array}$ & 30 \\
$\begin{array}{l}\text { Adopt a proactive search for market opportunities, } \\
\text { use market information to increase its profit }\end{array}$ & 25 \\
$\begin{array}{l}\text { Attempt to create customer value in order to } \\
\text { attract and retain customers, by delivering superior }\end{array}$ & 10 \\
$\begin{array}{l}\text { value to their target customers } \\
\text { Follow the strategy that achieving organizational } \\
\text { goals depends on knowing the needs and wants } \\
\text { of target markets and delivering the desired } \\
\text { satisfactions better than competitors do }\end{array}$ & 20 \\
$\begin{array}{l}\text { It focuses on creating sales transactions rather than } \\
\text { building long-term profitable customer relationships } \\
\text { To create a profitable relationship stakeholders }\end{array}$ & 5 \\
\hline \begin{tabular}{l} 
Total \\
\hline
\end{tabular} & 0 \\
\hline
\end{tabular}


Table 4: Agreement with statement indicating the importance of MKO concept

\begin{tabular}{|c|c|c|}
\hline \multirow[b]{2}{*}{ Statement } & \multicolumn{2}{|l|}{ Agreement } \\
\hline & Agree (\%) & Disagree $(\%)$ \\
\hline $\begin{array}{l}\text { Guide the organization to achieve its } \\
\text { objectives }\end{array}$ & 100 & 0 \\
\hline $\begin{array}{l}\text { Provides various ways and methods of } \\
\text { thinking }\end{array}$ & 98 & 2 \\
\hline $\begin{array}{l}\text { Makes management aware } \\
\text { of change in the environment and help } \\
\text { to adapt it. }\end{array}$ & 97 & 3 \\
\hline $\begin{array}{l}\text { Help better utilization of available } \\
\text { resources }\end{array}$ & 97 & 3 \\
\hline $\begin{array}{l}\text { Helps managers to be more creative } \\
\text { Provide a clear picture of MKO }\end{array}$ & 90 & 10 \\
\hline $\begin{array}{l}\text { CONCEPT processing across the } \\
\text { different organizational levels }\end{array}$ & 97 & 3 \\
\hline $\begin{array}{l}\text { Helps managers assess the philosophy } \\
\text { of the firm more logically }\end{array}$ & 100 & 0 \\
\hline $\begin{array}{l}\text { Clarifies the position of the } \\
\text { organization to all parties concerned }\end{array}$ & 95 & 5 \\
\hline
\end{tabular}

Table 5: Result of one-way ANOVA Kruskal Wallis for the clarity of the (MKO) concept according to years of experience*

\begin{tabular}{|c|c|c|c|c|}
\hline & \multicolumn{4}{|c|}{ Clarity of the MO concept } \\
\hline & \multicolumn{2}{|l|}{ Mean rank } & \multirow[b]{2}{*}{$x^{2}$} & \multirow[b]{2}{*}{$P$} \\
\hline Less than 10 years & $10-20$ years & 21 yearst & & \\
\hline 14.53 & 23.21 & 24.06 & 6.73 & 0.04 \\
\hline
\end{tabular}

provide various ways of thinking (98\%), understand and adapt to change (97\%), better utilize resources $(97 \%)$, improve creativity (90\%), provide clear vision of planning efforts in the firm (97\%), assess the philosophy of the firm more logically (100\%) and clarify the firm's position to all parties concerned (95\%).

The overall analysis leaves no doubts about the critical role of MKO concept in conducting of business in Jordanian service firms. Nevertheless, their actual behavior toward the MKO concept was apparently different. Subsequent analysis of the extent to which respondent firms make use of the MKO concept reveals that $(20 \%)$ of the firms followed MKO concept several times over the past 10 years. These further support their positive perception of the importance of the MKO concept, where as the concept itself was not very clear to them.

To answer the last research question, further analysis was carried out to examine any statistical differences $(\mathrm{p} \leq 0.05)$ in the clarity of the concept of the MKO concept due to organizational demographics (years of experience, number of employees and capital) One-Way ANOVA was used for this purpose.

Table 5 shows the result of the One-Way ANOVA testing the figures in the table show statistically significant differences in the clarity of the MKO concept according to the years of experience $(p=0.04)$.
Table 6: Result of one-way ANOVA Kruskal Wallis for the clarity of the (MKO) concept according to the number of employees* Clarity of the MO concept

\begin{tabular}{lllll} 
& \multicolumn{3}{c}{ Mean rank } & \\
Less than 50 & $50-150$ & $151+$ & $x^{2}$ & P \\
\hline 17.75 & 22.42 & 23.11 & 5.62 & 0.073 \\
\hline
\end{tabular}

Table 7: Result of one-way ANOVA Kruskal Wallis for the clarity of the (MKO) concept according to capital*

Clarity of the MO concept

\begin{tabular}{llll}
\multicolumn{4}{c}{ Mean rank } \\
Mreater than \\
1 million or less & $\begin{array}{l}\text { 1 million } \\
\text { 18.13 }\end{array}$ & $\mathrm{x}^{2}$ & $\mathrm{P}$ \\
\hline $\begin{array}{l}\text { *: Responses categories } \\
\text { analysis purposes }\end{array}$ & & 0.08 & 0.39 \\
\hline
\end{tabular}

The mean rank result in the table suggest that these differences were in favor of the most experience firms (21 years and above). Thus firms with 21 years experience or more were likely to be clear about the concept of the MKO concept than other younger firms. Perhaps, the longer years of experience in the business might have given them expertise and better vision in MKO concept.

Further testing for differences according to the number of employees and capital did not show statistically significant differences (Table 6 and 7).

\section{CONCLUSION}

In the light of the overall analysis the researchers arrives at the following conclusions: The concept of marketing orientation is not clear and not adopted by most of Jordanian service firms. The majority of Jordanian financial service firms had a misconception of marketing orientation concept. They believed that they exercise marketing orientation concept, while their actual practice of other orientations. The majority of these firms kept strategic planning at the top management level. Statistical testing shows that the length of experience in business was an important factor in the firm's clarity of the concept of marketing orientation.

The study recommends that Jordanian banks and financial institutions should rely more in consulting universities academic and other external expertise to update their knowledge through developing advance training programs and directing their effort toward customers' needs and wants.

\section{REFERENCES}

1. Armstrong, G. and P. Kotler, 2007. Marketing: An Introduction. 8th Edn., Pearson, Prentice-Hall, Upper Saddle River, New Jersey, pp: 522. 
2. Boone Louis, E. and L. Kurtz David, 2001. Contemporary Marketing. 10th Edn., Harcourt College Publishers, Philadelphia, ISBN: 0-3031403-8, pp: 619.

3. Cross, M.E., B.G. Thomas, E.R. Edward and N.D. Bellenger, 2007. Customer orientation and salesperson performance. Eur. J. Market., 41: 821-835. DOI: 10.1108/0309056071075410

4. O'cass, A. and N. Liem Viet, 2007. Market orientation versus innovative culture: Two routes to superior brand performance. Eur. J. Market., 41: 868-887. DOI: 10.1108/03090560710752438

5. Tse, A.C.B., Y.M.L. Sin, H.M.O. Yau, S.Y.J. Lee and R. Chow, 2004. A firm's role in the marketplace and the relative importance of market orientation and relationship marketing orientation. Eur. J. Market., 38: 1158-1172. DOI: 10.1108/03090560410548915

6. Farrelly, F. and P. Quester, 2003. The effects of market orientation on trust and commitment: The case of the sponsorship business-to-business relationship. Eur. J. Market., 37: 530-553. DOI: $10.1108 / 03090560310459078$
7. William, M.P. and O.C. Ferrell, 2006. Marketing concepts and Strategy. 13th Edn., Houghton Mifflin Company, Boston, New York, ISBN: 0618-47445-5, pp: 610.

8. Ellis, P.D., 2005. Marketing orientation and marketing practice in developing economy. Eur. J. Market., 39: 629-645. DOI: 10.1108/03090560510590746

9. Pulendran, S., R. Speed and R.E. Widing, 2003. Marketing planning, marketing orientation and business performance. Eur. J. Market., 37: 476-497. http://works.bepress.com/richard_speed/4/

10. Perry, M.L. and A.T. Shao, 2002. Marketing orientation and incumbent performance in dynamic market. Eur. J. Market., 36: 1140-1153. DOI: 10.1108/03090560210437370

11. Olivares, A.M. and N. Lado, 2003. Marketing orientation and business economic performance. Int. J. Serv. Ind. Manage., 14: 284-309. DOI: 10.1108/09564230310478837

12. Kotler, P. and G. Armstrong, 2008. Principle of Marketing. Pearson Education Upper Saddle River, New Jersey, ISBN: 13:978-0-13-239002-6, pp: 599. 